\title{
A Strain Rate Dependent Fracture Model of 7050 Aluminum Alloy
}

\author{
Jun Cao ${ }^{1, *} \mathbb{C}$, Fuguo $\mathrm{Li}^{2}{ }^{\mathbb{D}}$, Weifeng Ma ${ }^{1}$, Ke Wang ${ }^{1}$, Junjie Ren ${ }^{1}$, Hailiang $\mathrm{Nie}^{1}$ and \\ Wei Dang ${ }^{1}$ (D) \\ 1 Tubular Goods Research Institute of CNPC, Xi'an 710077, China; mawf@cnpc.com.cn (W.M.); \\ wangke003@cnpc.com.cn (K.W.); renjunjie@cnpc.com.cn (J.R.); nieh@cnpc.com.cn (H.N.); \\ buct_dangwei@163.com (W.D.) \\ 2 State Key Laboratory of Solidification Processing, School of Materials Science and Engineering, \\ Northwestern Polytechnical University, Xi'an 710072, China; fuguolx@nwpu.edu.cn \\ * Correspondence: caojun1@cnpc.com.cn; Tel.: +86-029-8188-7903 or +86-8188-7652
}

Received: 10 November 2019; Accepted: 13 December 2019; Published: 18 December 2019

\begin{abstract}
The purpose of this research is to predict fracture loci and fracture forming limit diagrams (FFLDs) considering strain rate for aluminum alloy 7050-T7451. A fracture model coupled Johnson-Cook plasticity model was proposed to investigate its strain rate effect. Furthermore, a hybrid experimental-numerical method was carried out to verify the strain rate-dependent fracture model by using fracture points of uniaxial tension, notched tension, flat-grooved tension, and pure shear specimens. The results show that the fracture points are in accordance with the fracture loci and FFLDs under different strain rates. The increasing strain rate decreases the FFLDs of aluminum alloy 7050-T7451. The difference of force-displacement responses under different strain rates is larger for notched tension and pure shear conditions.
\end{abstract}

Keywords: strain rate; fracture forming limit diagrams; fracture criterion; stress state; simulation

\section{Introduction}

Forming limit diagrams (FLD) have been widely used to predict the formability in the sheet metal forming processes, and it can be constructed by experiments such as Marciniak cup tests [1]. Fracture forming limit diagrams (FFLDs) present forming limits in the space of $\left(\varepsilon_{1}, \varepsilon_{2}\right)$ from the uniaxial compression to the balanced biaxial tension [2]. To fully investigate and understand the FFLDs of structural part under various strain rates, the research of mechanical behavior of materials under various loading paths becomes significant.

Some experimental studies have revealed that the mechanical behaviors of materials, including initial yield stress, plastic deformation evolution, and even the final fracture strain, present apparent difference under various strain rates [3-5]. Strain rate effect on necking behavior drew more attention because of its effect on local deformation [6].

Johnson-Cook (J-C) plasticity model represents the flow stress as a function of the equivalent plastic strain, strain rate, and temperature, and it has been widely used [7,8]. Swift model [9] is a classic constitutive equation to describe the stress-strain behavior of metallic alloy, it is a power-law equation, which can be coupled in the J-C plasticity model. The J-C plasticity model could be used to predict the viscoplastic response of materials when it is up to very high strains [10-12]. Xiao et al. [13] studied the fracture behavior of the ZK60 alloy by using modified J-C model by considering the effects of strain, stress state, and strain rate. A cryomilled nanostructured 5083 aluminum alloy exhibits the higher ductility at lower strain rates because of a diffusion-mediated stress relaxation mechanism [14]. 
The effect of strain rate on forming limit diagram (FLD) is different, Roth and Mohr [15] reported the increasing of strain rate increases the fracture loci for TRIP780 and DP590, while Lee et al. found [16] FLD of AZ31 alloy sheet was worse on higher strain rate and Mirfalah-Nasiri et al. [17] found that increasing of strain rate decreases the FLD of AA3104 sheet metal. In addition, Guo et al. [18] found that higher strain rate results in the decreasing of elongation to fracture for $\mathrm{Al}-\mathrm{Zn}-\mathrm{Mg}-\mathrm{Cu}$ alloy and Dong et al. [19] also found failure strain decreases with an increase in the strain rate of U-5.5Nb alloy. These results indicate the effect of strain rate on FLD is sensitive to materials. Khan and Liu [20] developed an isotropic ductile criterion by including strain rate and temperature dependences. The experimental results showed that in quasi-static loading region, the ductile fracture of the alloy was shown to have negligible strain rate dependence.

The purpose of this research is to predict fracture loci and FFLDs considering strain rate for aluminum alloy (AA) 7050-T7451. To investigate the effect of strain rate on the fracture loci and FFLDs of AA 7050-T7451, a strain rate dependent fracture model is proposed. The specimen geometries used in the analysis is to present strain evolution under various strain paths in the fracture loci or FFLDs. The experiments and simulations of uniaxial tension, notched tension, flat-grooved tension, and pure shear specimens on three strain rates, $0.001 \mathrm{~s}^{-1}, 0.01 \mathrm{~s}^{-1}$, and $0.1 \mathrm{~s}^{-1}$ were carried out to analyze the relation between strain rate and FFLDs. The results show that the strain histories come from verified finite element (FE) model agree with theoretical predictive fracture loci and FFLDs considering strain rate.

\section{Materials and Methods}

\subsection{Material and Experiment}

Uniaxial tension, notched tension, flat-grooved tension and pure shear experiments of AA 7050-T7451 were carried out on Instron 3382 at $0.001 \mathrm{~s}^{-1}, 0.01 \mathrm{~s}^{-1}$ and $0.1 \mathrm{~s}^{-1}$ which are quasi-static $\left(\leq 0.01 \mathrm{~s}^{-1}\right)$ and low-impact strain rates $\left(\leq 50 \mathrm{~s}^{-1}\right)$ [21]. The sizes and shapes of the four kinds of specimens are shown in the Figure 1a. In addition, the relative displacements for these experiments were measured using digital image correlation (DIC) technique which was explained in the Section 2.3. Prior to experiments with DIC technique, random speckle needs to be evenly distributed to a thin white layer on the specimen, as shown in Figure 1b. The images for DIC are obtained from the high-speed cameras.

The constitutive parameters of Swift model were determined by fitting the true stress-strain curve of AA7050-T7451 at $0.001 \mathrm{~s}^{-1}$, so $K, n$, and $\varepsilon_{0}$ were determined as $675 \mathrm{MPa}, 0.07642,-0.00114$, respectively. The parameters of strain rate-dependent fracture model are calculated according to the uniaxial tension and pure shear experiments [22], as listed in Table 1 (the parameters are defined in Section 2.4).

Table 1. The parameters of strain rate dependent fracture model.

\begin{tabular}{ccccc}
\hline Strain Rate & $\boldsymbol{\alpha}$ & $\boldsymbol{\beta}\left(\boldsymbol{R}_{\boldsymbol{\sigma}}>\mathbf{0}\right)$ & $\boldsymbol{\beta}\left(\boldsymbol{R}_{\boldsymbol{\sigma}}<\mathbf{0}\right)$ & $\boldsymbol{\tau}_{\mathbf{0}}$ \\
\hline $0.001 / \mathrm{s}$ & 0.1434 & 1 & 0.5 & 383 \\
$0.01 / \mathrm{s}$ & 0.1564 & 1 & 0.5 & 401 \\
$0.1 / \mathrm{s}$ & 0.1624 & 1 & 0.5 & 407 \\
\hline
\end{tabular}


(a)
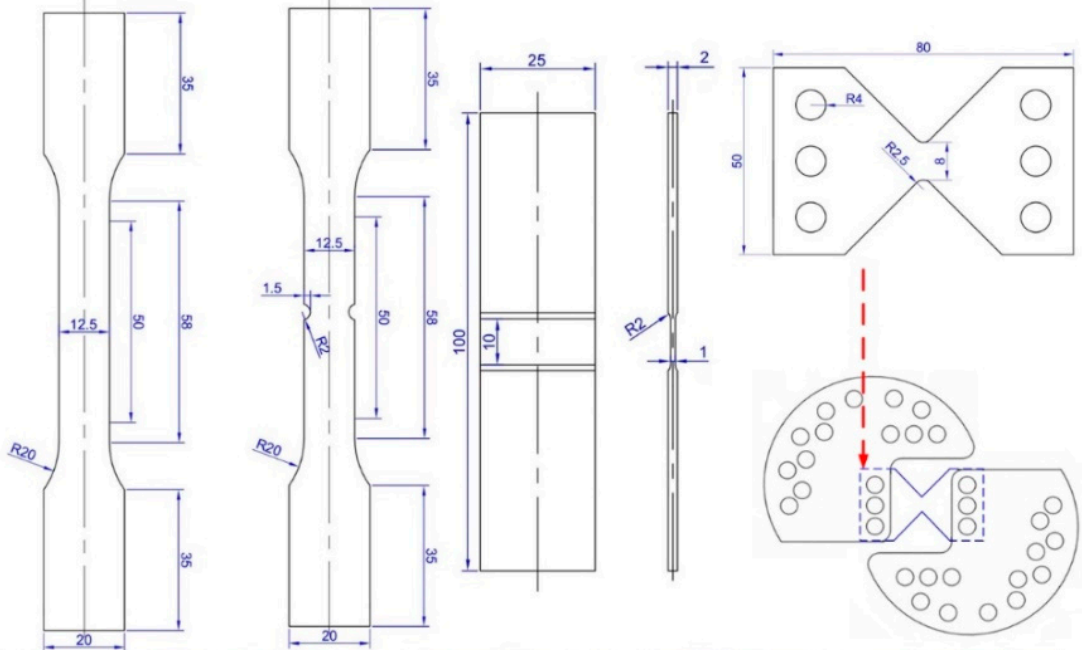

(b)

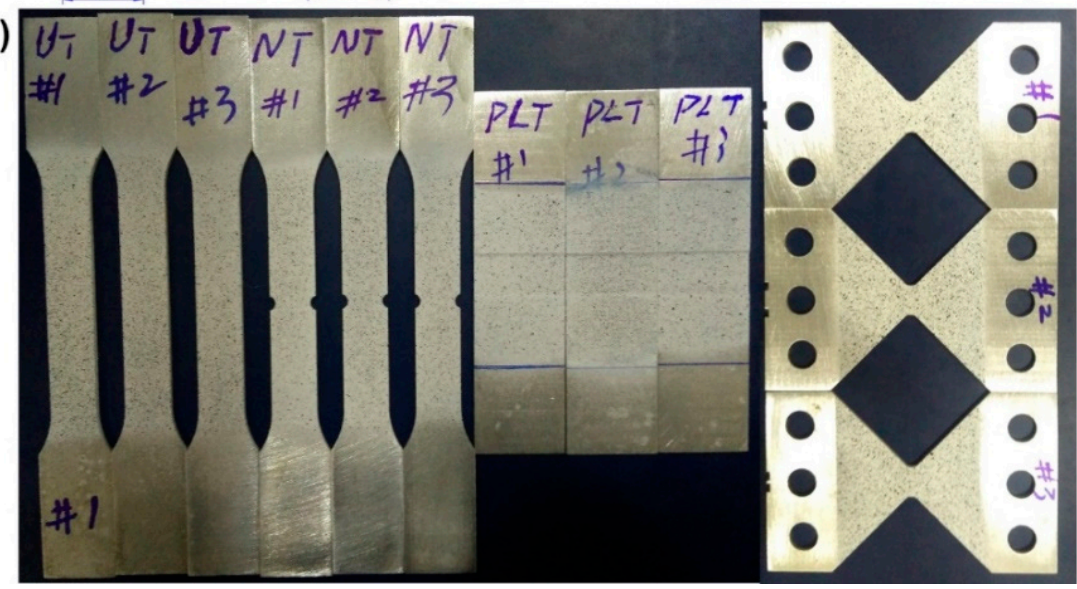

Figure 1. The (a) size and shape of uniaxial tension, notched tension, flat-grooved, and pure shear specimens and (b) actual four kinds of specimens.

\subsection{Numerical Simulation}

The numerical simulations of uniaxial tension, notched tension, flat-grooved tension, and pure shear specimens were conducted using commercial software ABAQUS 6.14 (SIMULIA, Wakeison France). The J-C plasticity model was employed through user subroutine. Since the symmetry of the tensile specimens, a quarter of uniaxial tension, notched tension, and flat-grooved tension specimens were applied in the 3D FE models. The eight-node hexahedra elements with reduced integration (C3D8R) were used and the meshes near the notches and grooves were refined.

\subsection{Digital Image Correlation Method}

Digital imaging correlation (DIC) is a technique which may prove to be ideally suited for the study of material deformation in real-world applications, as it has the potential to become a cheap, simple yet accurate solution [23]. DIC method was applied to obtain the local strain evolution and displacement of uniaxial tension, notched tension, flat-grooved tension, and pure shear specimens. The surfaces of four kinds of specimens were sprayed with a thin layer of white paint. Then some black speckles were evenly painted on the surfaces of the specimens. The DIC frame rate was set to $1 \mathrm{fps}, 10 \mathrm{fps}$, and 100 fps for the strain rates $0.001 \mathrm{~s}^{-1}, 0.01 \mathrm{~s}^{-1}$, and $0.1 \mathrm{~s}^{-1}$. The optical measurements were done using the XITUDIC_VS system ( $\mathrm{Xi}^{\prime}$ an Jiaotong University, $\mathrm{Xi}^{\prime}$ an, China) with 6-megapixel resolution of cameras. To reduce noise, the strain filter used a $3 \times 3$ square elements and to calculate the strain value of center point. The $3 \times 3$ square elements $(3 \times 3 \times 13$ pixel $)$ was chosen to calculate the local strain. 


\subsection{Theoretical Method}

The J-C plasticity model took the effect of strain hardening, strain rate, and temperature into account, respectively. It is widely used in the numerical analysis under dynamic loading and high temperature condition. The constitutive equation of J-C plasticity model is expressed as,

$$
f\left(\bar{\varepsilon}_{p}, \dot{\bar{\varepsilon}}_{p}, T\right)=f_{\varepsilon}\left(\bar{\varepsilon}_{p}\right) f_{\dot{\varepsilon}}\left(\dot{\bar{\varepsilon}}_{p}\right) f_{T}(T)
$$

The Swift hardening model is applied in the J-C plasticity model. It is expressed as

$$
f_{\varepsilon}\left(\bar{\varepsilon}_{p}\right)=K\left(\bar{\varepsilon}_{p}+\varepsilon_{0}\right)^{n}
$$

where $K$ is strength coefficient, $\bar{\varepsilon}_{p}$ is equivalent plastic strain, $\varepsilon_{0}$ is offset strain, $n$ is strain hardening index. The function in terms of strain rate is presented as

$$
f_{\dot{\varepsilon}}\left(\dot{\bar{\varepsilon}}_{p}\right)= \begin{cases}1 & , \dot{\bar{\varepsilon}}_{p}<\dot{\bar{\varepsilon}}_{0} \\ 1+C \ln \left(\frac{\dot{\bar{\varepsilon}}_{p}}{\overline{\bar{\varepsilon}}_{0}}\right) & , \dot{\bar{\varepsilon}}_{p}>\dot{\bar{\varepsilon}}_{0}\end{cases}
$$

where the reference strain rate $\dot{\bar{\varepsilon}}_{p}$ is taken as 0.001 under quasi-static loading condition and $C$ is sensitivity coefficient of strain rate which can be fitted. In this study, the effect of temperature is not considered, and all the experiments were carried out at the room temperature, therefore, $f_{T}(T)=1$ in this study. The parameter $C$ is determined by fitting the relationship between $\sigma / K\left(0.002+\varepsilon_{0}\right)^{n}$ and $\dot{\bar{\varepsilon}}_{P} / \dot{\bar{\varepsilon}}_{0}$, and the $C$ is determined as 0.03529 .

A modified elliptical fracture criterion was proposed based on the strain energy density [22]. It is expressed as

$$
\tau^{2}+\alpha^{2} \beta \sigma^{2} \operatorname{sgn}(\sigma)=\tau_{0}^{2}
$$

where $\alpha$ is intrinsic parameter which is $\tau_{0} / \sigma_{0}$. $\tau_{0}$ is critical shear stress, $\sigma_{0}$ is critical normal stress, $\beta$ is external parameter, $\operatorname{sgn}(\sigma)$ is symbolic function which is 1 when normal stress $\sigma>0$ and is -1 when normal stress $\sigma<0$.

Based on the derivation process of the modified elliptical fracture criterion in [22], equivalent stress can be expressed as:

$$
\bar{\sigma}^{2}=\frac{\left(1-\alpha^{2} \beta^{*}\right) \tau_{0}^{2}}{\alpha^{2} \beta^{*}\left(R_{\sigma}-\frac{L}{3 \sqrt{L^{2}+3}}\right)^{2}+\left(1-\alpha^{2} \beta^{*}\right)\left(\frac{1}{\sqrt{L^{2}+3}}\right)^{2}}
$$

where $R_{\sigma}$ is stress triaxiality, $L$ is Lode parameter, $\beta^{*}$ is $\beta$ when $\sigma>0, \beta^{*}$ is $-\beta$ when $\sigma<0$. In order to obtain the expression of equivalent plastic strain $\bar{\varepsilon}_{p}$ in the space of $\left(R_{\sigma}, L, \bar{\varepsilon}_{p}\right)$, the J-C plasticity model needs to be substituted into the Equation (5). Therefore, the J-C plasticity model is coupled in the modified elliptical fracture criterion in the expression of $\bar{\varepsilon}_{p}$. So $\bar{\varepsilon}_{p}$ is expressed as:

$$
\bar{\varepsilon}_{p}= \begin{cases}\left(\frac{\left(1-\alpha^{2}\right) \tau_{0}^{2}}{\alpha^{2} K^{2}\left(R_{\sigma}-\frac{L}{3 \sqrt{L^{2}+3}}\right)+K^{2}\left(1-\alpha^{2}\right)\left(\frac{1}{\sqrt{L^{2}+3}}\right)^{2}}\right)^{1 / 2 n}-\varepsilon_{0} & , \dot{\bar{\varepsilon}}_{P}<\dot{\bar{\varepsilon}}_{0} \\ \left(\frac{\left(1-\alpha^{2}\right) \tau_{0}^{2}}{\alpha^{2} K^{2}\left(1+C \ln \left(\frac{\dot{\bar{\varepsilon}} P}{\bar{\varepsilon}_{0}}\right)\right)^{2}\left(R_{\sigma}-\frac{L}{3 \sqrt{L^{2}+3}}\right)+K^{2}\left(1+C \ln \left(\frac{\dot{\bar{\varepsilon}}}{\overline{\bar{\varepsilon}}_{0}}\right)\right)^{2}\left(1-\alpha^{2}\right)\left(\frac{1}{\sqrt{L^{2}+3}}\right)^{2}}\right)^{1 / 2 n}-\varepsilon_{0} & , \dot{\bar{\varepsilon}}_{P}>\dot{\bar{\varepsilon}}_{0}\end{cases}
$$

FFLD and fracture loci in strain spaces with consideration of strain rate were constructed based on the Equation (6) and the assumption of proportional straining, and the plotting method were illustrated in [22]. 


\section{Results}

Figures 2-5 show force-displacement responses and local equivalent plastic strain versus displacement between experiments and simulations at the strain rates of $0.001 \mathrm{~s}^{-1}, 0.01 \mathrm{~s}^{-1}$, and $0.1 \mathrm{~s}^{-1}$ for uniaxial tension, notched tension, flat-grooved, and pure shear specimens, additionally, the contour maps between DIC technique and simulation near fracture point are inserted in the figures. The comparisons between experiments and simulations present good agreement, which validate the correctness of FE models. In the Figure 2, the ultimate tensile strength (UTS) increases with the increase of strain rate, this reason is discussed in the next paragraph. In addition, the local strain at lowest strain rate are the largest. In the Figure 3, the effect of strain rate on fracture displacement for notched tension specimen is remarkable and the fracture displacement at highest strain rate is lowest. In the Figure 4, the failure region under plane strain tension is concentrated in the center and the effect of strain rate does not largely affect the force and displacement. In the Figure 5, the necking regions of pure shear specimens are largely influenced by strain rate, and the higher strain rate leads to the smaller necking degree. The stress triaxiality of flat-grooved process is largest and that of pure shear process is lowest. The stress triaxiality is the ratio of mean stress to equivalent stress, which indicates that the ratio of volume deformation to shape deformation. Therefore, the process of dislocation motion for pure shear is largest since the ability of shape deformation is largest, and then the strain rate has larger effect on the pure shear deformation. Since stress concentration exists in the notched tension process, the strain rate only affects the hardening behavior in the root of notch. The plastic deformation at the root of notch proceeds more adequately at lowest strain rate. So, the fracture displacement of notched tension specimen is largest at the lowest strain rate.
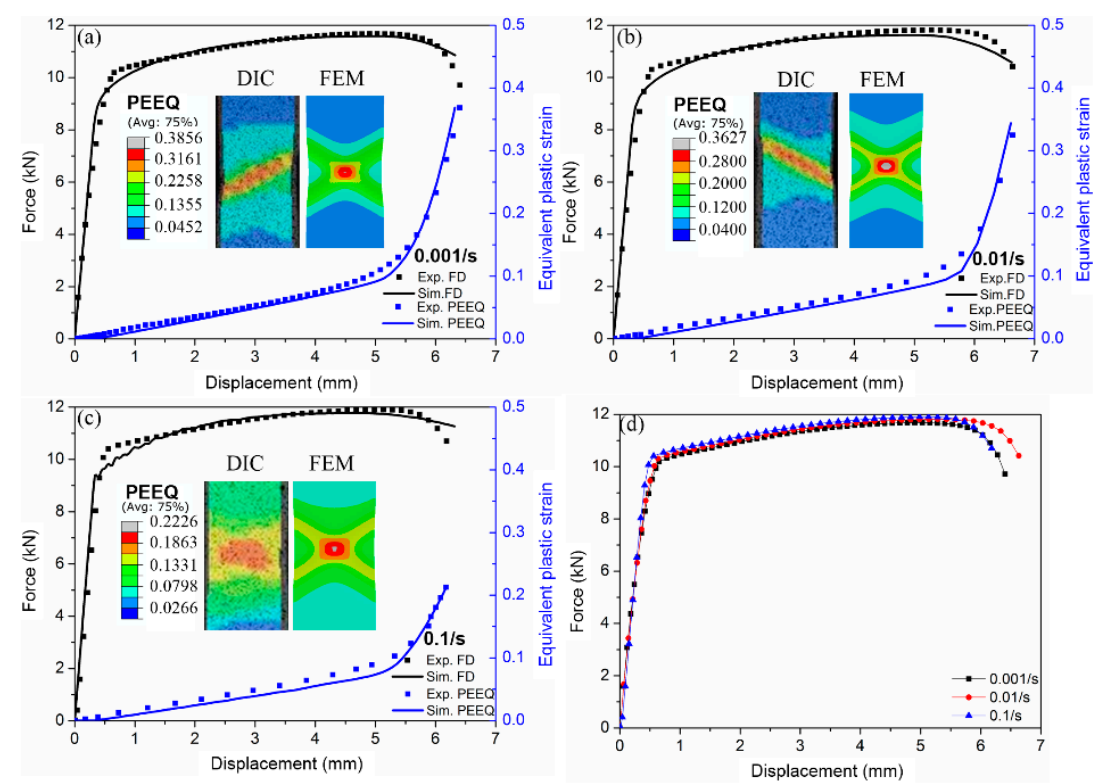

Figure 2. Force-displacement responses and local equivalent plastic strain versus displacement of uniaxial tension specimens between experiments and simulations with (a) $0.001 \mathrm{~s}^{-1}$, (b) $0.01 \mathrm{~s}^{-1}$, (c) $0.1 \mathrm{~s}^{-1}$, and (d) three strain rates. (PEEQ is abbreviation of equivalent plastic strain). 

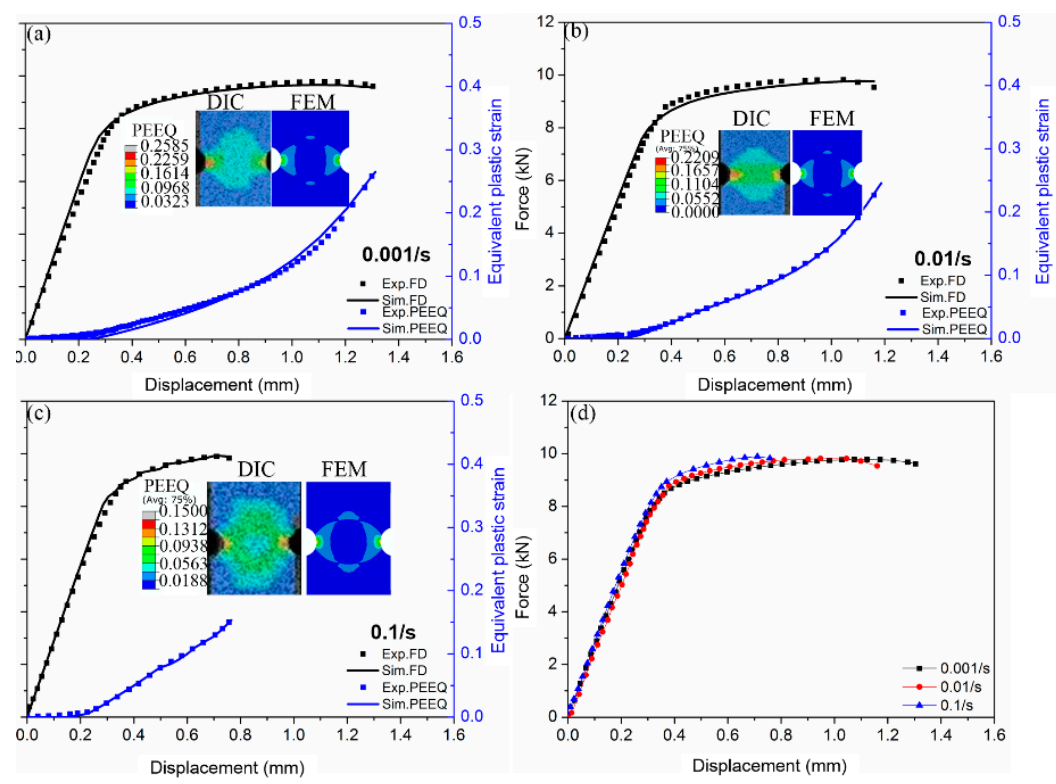

Figure 3. Force-displacement responses and local equivalent plastic strain versus displacement of notched tension specimens between experiments and simulations with (a) $0.001 \mathrm{~s}^{-1}$, (b) $0.01 \mathrm{~s}^{-1}$, (c) $0.1 \mathrm{~s}^{-1}$, and (d) three strain rates.
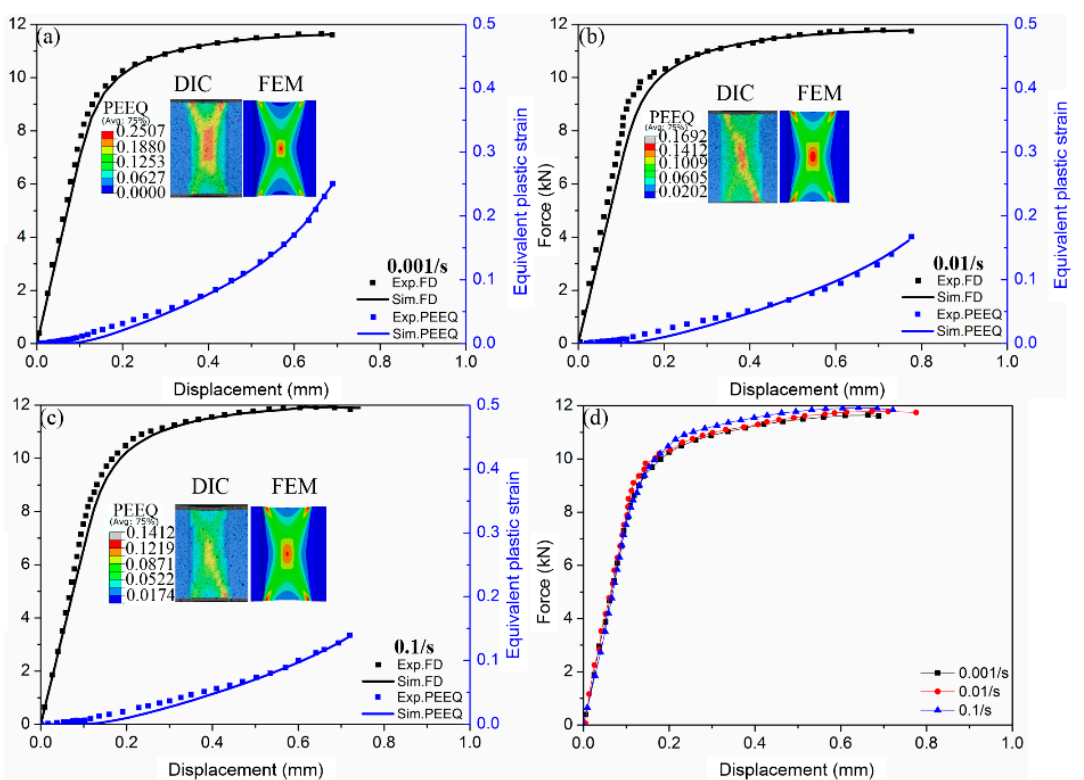

Figure 4. Force-displacement responses and local equivalent plastic strain versus displacement of flat-grooved specimens between experiments and simulations with (a) $0.001 \mathrm{~s}^{-1}$, (b) $0.01 \mathrm{~s}^{-1}$, (c) $0.1 \mathrm{~s}^{-1}$, and (d) three strain rates.

Figure 6 shows the experimental yield strengths (YS) and UTS of AA7050-T7451 at $0.001 \mathrm{~s}^{-1}$, $0.01 \mathrm{~s}^{-1}$, and $0.1 \mathrm{~s}^{-1}$ of strain rates based on Figure 2. It reflects that the effect of strain rate on YS is larger than that on UTS. Since the mechanisms of yielding and hardening saturation process are different, the two processes are initial and final stage of plastic deformation. In the initial stage, only one slip system may be at work and the effect of work hardening is not obvious. However, in the final stage of plastic deformation, two or more intersecting slip surfaces slide along a slip direction, the effect of work hardening gradually decreases. Therefore, the strain rate effect has large influence at yielding stage, while it plays a less role at saturate work hardening stage. 

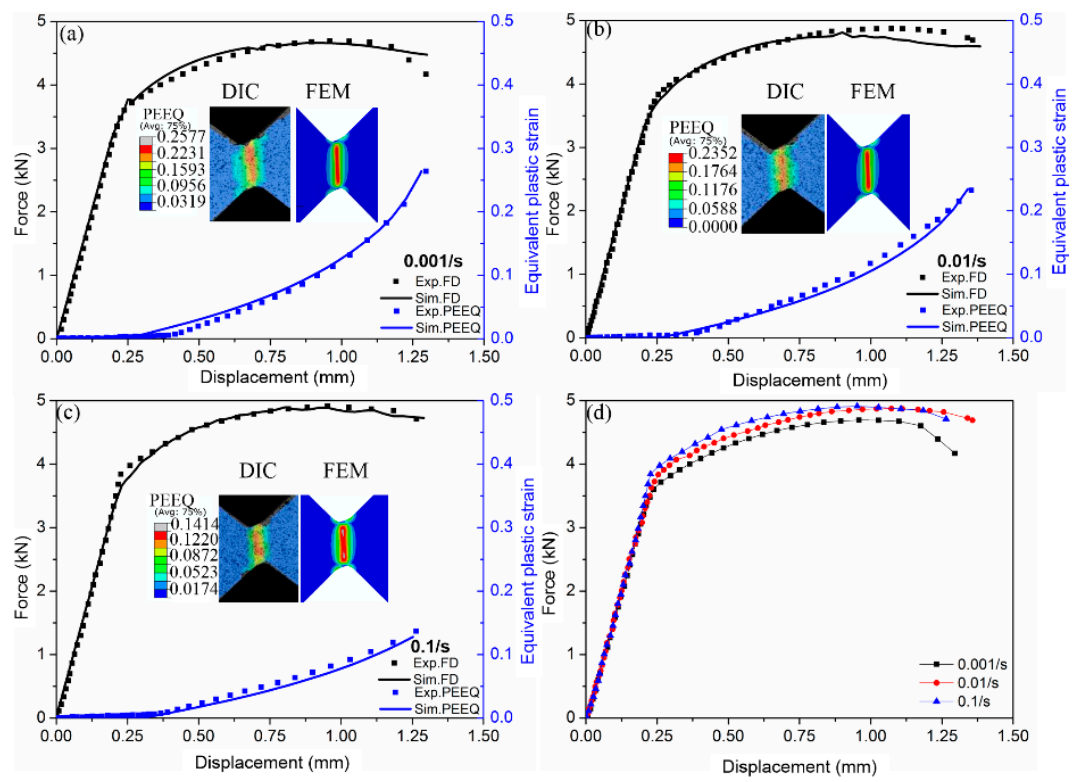

Figure 5. Force-displacement responses and local equivalent plastic strain versus displacement of pure shear specimens between experiments and simulations with (a) $0.001 \mathrm{~s}^{-1}$, (b) $0.01 \mathrm{~s}^{-1}$, (c) $0.1 \mathrm{~s}^{-1}$, and (d) three strain rates.

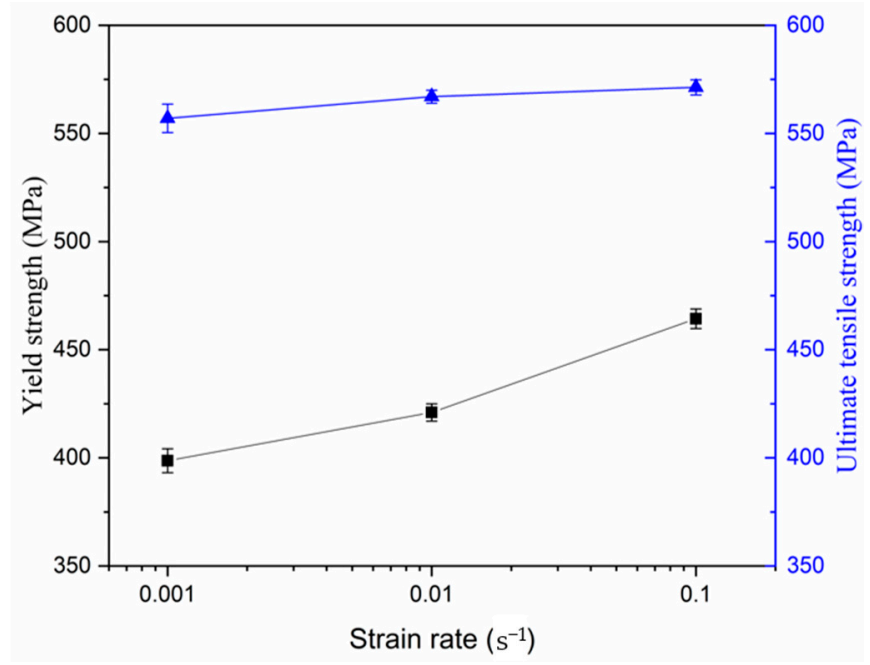

Figure 6. The effect of strain rate on yield strength and ultimate tensile strength of AA7050-T7451.

Figure 7 shows FFLDs at the three strain rates $\left(0.001 \mathrm{~s}^{-1}, 0.01 \mathrm{~s}^{-1}\right.$, and $\left.0.1 \mathrm{~s}^{-1}\right)$ and the loading histories with experimental fracture strain for the four kinds of specimens. The four fracture points are in good accordance with the FFLDs at three strain rates. It indicates that the forming ability decreases with the increase of strain rate. For instance, the major strain of uniaxial tension specimen at $0.001 \mathrm{~s}^{-1}$ of strain rate is $\sim 0.4$ while it reduces to $\sim 0.2$ at $0.1 \mathrm{~s}^{-1}$ and the necking degree is not obvious. It indicates that the high strain rate improves the brittleness of AA 7050-T7451. From the variation of loading paths for the four kinds of specimens, the loading path becomes more and more straight which indicates that the degree of local deformation decreases with the increasing of strain rate. Hence, the fracture strain is largely affected by the local deformation which is largely affected by the strain rate effect. 


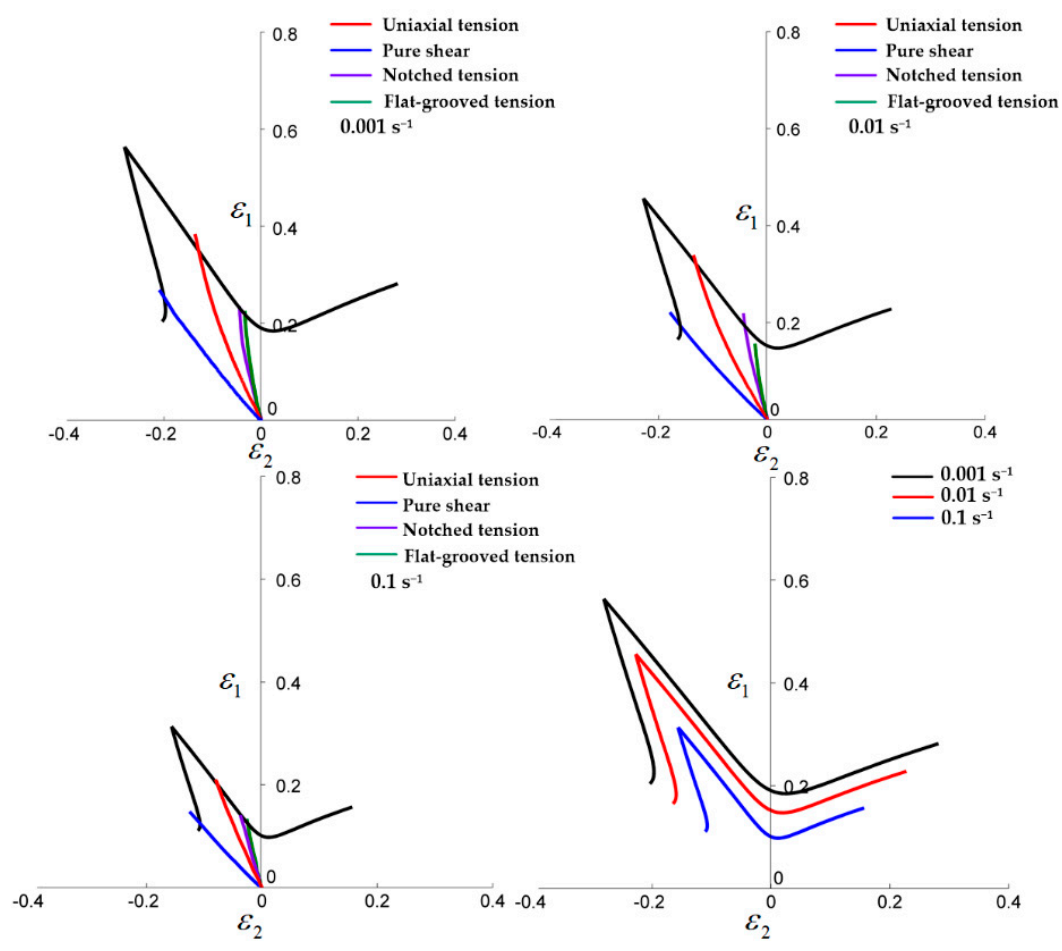

Figure 7. Fracture forming limit diagrams (FFLDs) and the loading histories of experimental strain for uniaxial tension, notched tension, flat-grooved tension, and pure shear specimen with (a) $0.001 \mathrm{~s}^{-1}$, (b) $0.01 \mathrm{~s}^{-1}$, (c) $0.1 \mathrm{~s}^{-1}$, and (d) three strain rates.

Figure 8 shows the fracture loci in the space of $\left(R_{\sigma}, \bar{\varepsilon}_{p}\right)$ and strain histories versus stress triaxiality at three strain rates $\left(0.001 \mathrm{~s}^{-1}, 0.01 \mathrm{~s}^{-1}\right.$, and $\left.0.1 \mathrm{~s}^{-1}\right)$ for the four kinds of specimens. The comparisons between fracture loci and fracture points at $0.001 \mathrm{~s}^{-1}, 0.01 \mathrm{~s}^{-1}$, and $0.1 \mathrm{~s}^{-1}$ are consistent. The strain is obtained from DIC measurement and the stress triaxiality is obtained from FE models. The stress triaxiality of uniaxial tension, notched tension, and flat tension deformation are concentrated in $0.3 \sim 0.5$ and the stress triaxiality increases with the process of plastic deformation. In addition, the stress triaxiality of pure shear specimen is concentrated in $0 \sim 0.1$. These changes of stress triaxiality reflect the degree of local deformation under various strain rates. It also indicates that the extent of strain rate effect is larger for pure shear and uniaxial tension processes. Meanwhile, the difference between largest and lowest equivalent plastic strain gradually decreases with the increase of strain rate because of the lack of sliding time at higher strain rate.

Figure 9 shows the fracture surfaces in the space of $\left(R_{\sigma}, L, \bar{\varepsilon}_{p}\right)$ at the three strain rates and the loading histories of the four kinds of specimens. The loading histories with stress triaxiality and Lode parameter of the four kinds of specimens reflect the evolution of stress states and strain states. The four fracture points agree with the fracture surfaces at the three strain rates $\left(0.001 \mathrm{~s}^{-1}, 0.01 \mathrm{~s}^{-1}\right.$, and $\left.0.1 \mathrm{~s}^{-1}\right)$. 

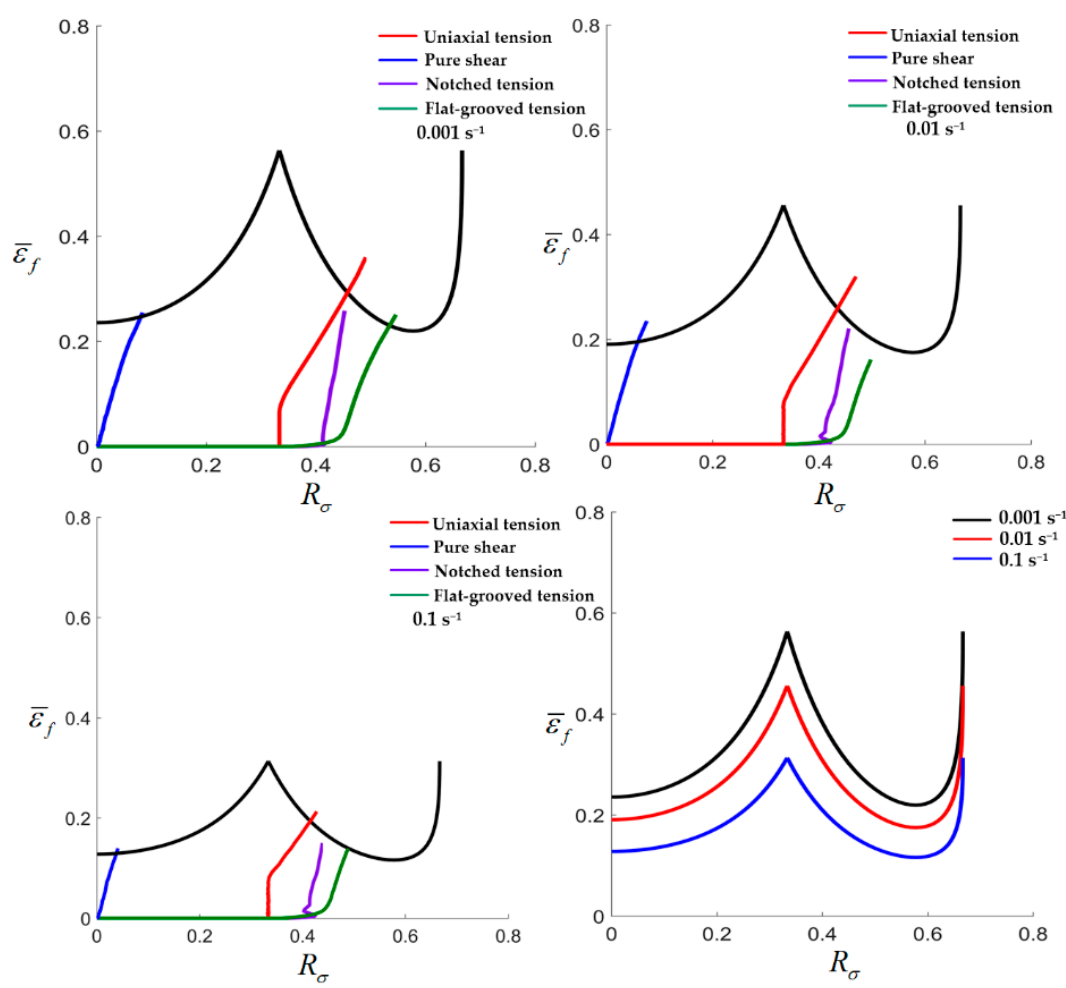

Figure 8. Fracture loci in the space of $\left(R_{\sigma}, \bar{\varepsilon}_{p}\right)$ and the loading histories of experimental strain for uniaxial tension, notched tension, flat-grooved tension, and pure shear specimen with (a) $0.001 \mathrm{~s}^{-1}$, (b) $0.01 \mathrm{~s}^{-1}$, (c) $0.1 \mathrm{~s}^{-1}$, and (d) three strain rates.
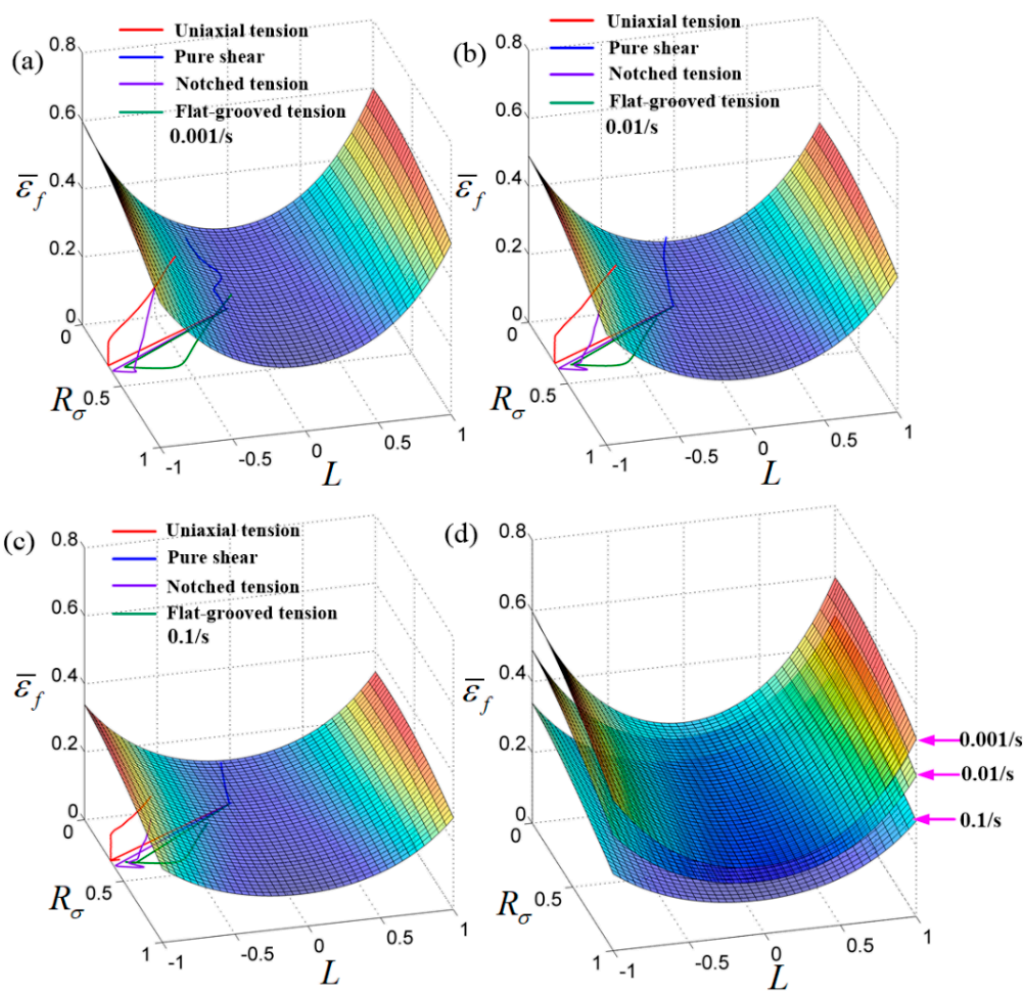

Figure 9. Fracture loci in the space of $\left(R_{\sigma}, L, \bar{\varepsilon}_{p}\right)$ and the loading histories of experimental strain for uniaxial tension, notched tension, flat-grooved tension, and pure shear specimen with (a) $0.001 \mathrm{~s}^{-1}$, (b) $0.01 \mathrm{~s}^{-1}$, (c) $0.1 \mathrm{~s}^{-1}$, and (d) three strain rates. 


\section{Discussion}

From Figure 9, the differences of fracture loci at $L=-1$ and $L=0$ with different strain rates are different. The equivalent plastic strain is largest at $L=-1$ and $L=1$, and the strain rate effect is larger at these two strain states (normalized uniaxial tension and normalized uniaxial compression state) [24]. In order to explain this issue, the distortional strain energy density [22] is introduced:

$$
(\mathrm{d} W / \mathrm{d} V)_{\mathrm{d}}=(1+v)\left[\left(\sigma_{1}-\sigma_{2}\right)^{2}+\left(\sigma_{2}-\sigma_{3}\right)^{2}+\left(\sigma_{1}-\sigma_{3}\right)^{2}\right] / 6 E
$$

Since Lode parameter factually is representation of the effect of second principal stress $\sigma_{2}$, the maximum value of $(\mathrm{d} W / \mathrm{d} V)_{\mathrm{d}}$ is determined when $\sigma_{2}$ is $\left(\sigma_{1}+\sigma_{3}\right) / 2$ and $L=\left(2 \sigma_{2}-\sigma_{1}-\sigma_{3}\right) /\left(\sigma_{1}-\sigma_{3}\right)$. So the $(\mathrm{d} W / \mathrm{d} V)_{\mathrm{d}}$ is minimum value when $L=0$, and $(\mathrm{d} W / \mathrm{d} V)_{\mathrm{d}}$ is larger when $L=1$ and $L=-1$. $(\mathrm{d} W / \mathrm{d} V)_{\mathrm{d}}$ is representation of the ability of shape deformation, hence, the effect of strain rate on fracture loci is larger when $L=-1$ and $L=1$. It is because that the strain rate can largely affect the dislocation movement.

Since the strain rate of $0.001 \mathrm{~s}^{-1}, 0.01 \mathrm{~s}^{-1}$, and $0.1 \mathrm{~s}^{-1}$ are quasi-static and low impact loading conditions [21], the dynamic effects are not significant for tension and shear behavior. The effect of strain rate on failure strain mainly depends on the responses of necking behavior. Within the range of quasi-static and low impact loading conditions, with the increase of strain rate, the resistance of dislocation movement in materials increases, which leads to dislocation accumulation in local areas of materials, thus the yield stress and tensile strength of materials slightly increases, and decreasing the uniform elongation significantly, leading to the early fracture of materials, which reduces the fracture strain of the materials. However, in the range of high strain rate, damage and adiabatic temperature rise may occur during plastic deformation, resulting in different degrees of reduction of deformation resistance, and increase of fracture strain [15].

\section{Conclusions}

Based on J-C plasticity model and a modified elliptical fracture criterion, a strain rate-dependent fracture criterion was proposed to predict fracture loci in strain spaces and FFLD of AA 7050-T7451. Experiments and simulations of uniaxial tension, notched tension, flat-grooved, and pure shear specimens were carried out to analyze the effect of strain rate on fracture loci and FFLD. The conclusions can be drawn as follows.

(1) The FFLDs and fracture loci decrease with the increase of strain rate under $0.001 \mathrm{~s}^{-1}, 0.01 \mathrm{~s}^{-1}$, and $0.1 \mathrm{~s}^{-1}$. These results indicate that the ductility under different strain paths reduces as increasing the strain rate. The effect of strain rate on YS is larger than that of UTS of AA7050-T7451. It reflects that the strain rate effect has large influence at the initial stage of plastic deformation, while it plays a lesser role at the saturate work hardening stage.

(2) The UTS increases with the increase of strain rate, and the local strain at lowest strain rate is largest for uniaxial tension specimen. The effect of strain rate on fracture displacement for notched tension specimen is remarkable and the fracture displacement at highest strain rate is lowest. The necking regions are influenced by strain rate under pure shear loading and higher strain rate leading to smaller necking degree.

(3) The FFLDs, fracture loci in the space of $\left(R_{\sigma}, \bar{\varepsilon}_{p}\right)$ and the fracture loci in the space of $\left(R_{\sigma}, L, \bar{\varepsilon}_{p}\right)$ at three strain rates are consistent with the fracture points of experimental strain for uniaxial tension, notched tension, flat-grooved tension, and pure shear specimens. It verifies the correctness of the strain rate-dependent fracture model of AA 7050-T7451.

Author Contributions: J.C. and F.L. conceived and designed the experiments, derived the theoretical framework, conducted writing-original draft preparation. W.M. revised the original draft and provided constructive suggestions. K.W. and J.R. performed the experiments. H.N. and W.D. performed the simulations. All authors have read and agreed to the published version of the manuscript. 
Funding: This research was funded by the National Science Foundation for Young Scientists of China, grant number 51904332, and the APC was funded by National Key R\&D Program of China, grant number 2016YFC0802101, and the State Key Laboratory of Solidification Processing (NWPU) of China, grant number 130-QP-2015.

Acknowledgments: This research is supported by the technical support from the Science and Education Practice and Material Analysis Innovation Center of Northwestern Polytechnical University. We also would like to thank the assistance from the research group of Fuguo Li.

Conflicts of Interest: The authors declare no conflict of interest.

\section{References}

1. Marciniak, Z.A.; Kuczyński, K.; Pokora, T. Influence of the plastic properties of a material on the forming limit diagram for sheet metal in tension. Int. J. Mech. Sci. 1973, 15, 789-800. [CrossRef]

2. Lou, Y.; Huh, H.; Lim, S.; Pack, K. New ductile fracture criterion for prediction of fracture forming limit diagrams of sheet metals. Int. J. Solids Struct. 2012, 49, 3605-3615. [CrossRef]

3. Hopperstad, O.S.; Børvik, T.; Langseth, M.; Labibes, K.; Albertini, C. On the influence of stress triaxiality and strain rate on the behaviour of a structural steel. Part I. Experiments. Eur. J. Mech. 2003, 22, 1-13. [CrossRef]

4. Clausen, A.H.; Børvik, T.; Hopperstad, O.S.; Benallal, A. Flow and fracture characteristics of aluminium alloy AA5083-H116 as function of strain rate, temperature and triaxiality. Mater. Sci. Eng. A 2004, 364, $260-272$. [CrossRef]

5. Liu, Y.J.; Sun, Q. A dynamic ductile fracture model on the effects of pressure, Lode angle and strain rate. Mater. Sci. Eng. A 2014, 589, 262-270. [CrossRef]

6. Sato, K.; Yu, Q.; Hiramoto, J.; Urabe, T.; Yoshitake, A. A method to investigate strain rate effects on necking and fracture behaviors of advanced high-strength steels using digital imaging strain analysis. Int. J. Impact Eng. 2015, 75, 11-26. [CrossRef]

7. Qiao, J.W.; Chu, M.Y.; Cheng, L.; Ye, H.Y.; Yang, H.J.; Ma, S.G.; Wang, Z.H. Plastic flows of in-situ metallic glass matrix composites upon dynamic loading. Mater. Lett. 2014, 119, 92-95. [CrossRef]

8. Farahani, H.K.; Ketabchi, M.; Zangeneh, S. Determination of Johnson-Cook Plasticity Model Parameters for Inconel718. J. Mater. Eng. Perform. 2017, 26, 5284-5293. [CrossRef]

9. Swift, H.W. Plastic instability under plane stress. J. Mech. Phys. Solids 1952, 1, 1-18. [CrossRef]

10. Verleysen, P.; Peirs, J.; Van Slycken, J.; Faes, K.; Duchene, L. Effect of strain rate on the forming behaviour of sheet metals. J. Mater. Process. Technol. 2011, 211, 1457-1464. [CrossRef]

11. Erice, B.; Gálvez, F.; Cendón, D.A.; Sánchez-Gálvez, V. Flow and fracture behaviour of FV535 steel at different triaxialities, strain rates and temperatures. Eng. Fract. Mech. 2012, 79, 1-17. [CrossRef]

12. Kajberg, J.; Sundin, K.-G. Material characterisation using high-temperature Split Hopkinson pressure bar. J. Mater. Process. Technol. 2013, 213, 522-531. [CrossRef]

13. Yue, X.; Qi, T.; Hu, Y.; Jian, P.; Luo, W. Flow and Fracture Study for ZK60 Alloy at Dynamic Strain Rates and Different Loading States. Mater. Sci. Eng. A 2018, 724, 208-219.

14. Han, B.Q.; Huang, J.Y.; Zhu, Y.T.; Lavernia, E.J. Effect of strain rate on the ductility of a nanostructured aluminum alloy. Scr. Mater. 2006, 54, 1175-1180. [CrossRef]

15. Roth, C.C.; Mohr, D. Effect of strain rate on ductile fracture initiation in advanced high strength steel sheets: Experiments and modeling. Int. J. Plast. 2014, 56, 19-44. [CrossRef]

16. Lee, Y.; Kwon, Y.; Kang, S.; Kim, S.; Lee, J. Forming limit of AZ31 alloy sheet and strain rate on warm sheet metal forming. J. Mater. Process. Technol. 2008, 201, 431-435. [CrossRef]

17. Mirfalah-Nasiri, S.; Basti, A.; Hashemi, R. Forming limit curves analysis of aluminum alloy considering the through-thickness normal stress, anisotropic yield functions and strain rate. Int. J. Mech. Sci. 2016, 117, 93-101. [CrossRef]

18. Yue, G.; Zhou, M.; Sun, X.; Long, Q.; Li, L.; Xie, Y.; Liu, Z.; Di, W.; Yang, L.; Tong, W. Effects of Temperature and Strain Rate on the Fracture Behaviors of an Al-Zn-Mg-Cu Alloy. Materials 2018, 11, 1233.

19. Dong, C.; Chen, X.; Rong, M.; Tang, Q.; Su, B.; Wang, Z.; Zhang, X.; Meng, D. Effect of strain rate on fracture of U-5.5Nb alloy. Mater. Sci. Technol. 2018, 34, 12-19.

20. Khan, A.S.; Liu, H. Strain rate and temperature dependent fracture criteria for isotropic and anisotropic metals. Int. J. Plast. 2012, 37, 1-15. [CrossRef] 
21. Safari, M.; Azodi, H.D. An investigation into the effect of strain rate on forming limit diagram using ductile fracture criteria. Meccanica 2012, 47, 1391-1399. [CrossRef]

22. Cao, J.; Li, F.; Ma, X.; Sun, Z. A modified elliptical fracture criterion to predict fracture forming limit diagrams for sheet metals. J. Mater. Process. Technol. 2018, 252, 116-127. [CrossRef]

23. Mccormick, N.; Lord, J. Digital Image Correlation. Mater. Today 2010, 13, 52-54. [CrossRef]

24. Lou, Y.; Yoon, J.W.; Huh, H. Modeling of shear ductile fracture considering a changeable cut-off value for stress triaxiality. Int. J. Plast. 2014, 54, 56-80. [CrossRef] 